Abstract THU0348 - Table 1. Univariate Cox proportional hazard modelling investigating the association of various parameters and mortality showing that only one modifiable risk factor associated with prognosis (time on dialysis, the longer on dialysis the worse the prognosis) and one non-modifiable (rTp taking place after 2000 associated with better survival). SLE- Systemic Lupus Erythematosous, LN- Lupus Nephritis, ESRF- End Stage Renal Failure, rTp- renal transplantation, PD- Peritoneal Dialysis, HD- Haemodialysis, APLS Antiphospholipid syndrome, MI- Myocardial Infarction, TIA- Transient Ischaemic Attack.

\begin{tabular}{|c|c|c|c|}
\hline Factor & $\begin{array}{c}P \\
\text { value }\end{array}$ & HR & $95 \% \mathrm{Cl}$ \\
\hline Time on Dialysis/per month & 0.031 & 1.013 & $\begin{array}{c}1.001- \\
1.026\end{array}$ \\
\hline Gender/male & 0.442 & 0.038 & $\begin{array}{c}0.001- \\
161.3\end{array}$ \\
\hline Ethnicity & 0.987 & 0.995 & $\begin{array}{c}0.537- \\
1.844\end{array}$ \\
\hline Age at SLE diagnosis & 0.552 & 1.021 & $\begin{array}{c}0.953- \\
1.094\end{array}$ \\
\hline Age of LN & 0.941 & 1.003 & $\begin{array}{c}0.920- \\
1.092\end{array}$ \\
\hline Age at $r T p$ & 0.431 & 1.026 & $\begin{array}{c}0.963- \\
1.092\end{array}$ \\
\hline Dialysis PD (vs HD) & 0.764 & 0.706 & $\begin{array}{c}0.073- \\
6.862\end{array}$ \\
\hline Time between LN and Dialysis & 0.540 & 0.999 & $\begin{array}{c}0.994- \\
1.003\end{array}$ \\
\hline LN Duration before Dialysis & 0.152 & 1.066 & $\begin{array}{c}0.977- \\
1.164\end{array}$ \\
\hline Type IV LN & 0.398 & 2.533 & $\begin{array}{c}0.294- \\
21.82\end{array}$ \\
\hline Dialysis Decade & 0.712 & 0.872 & $\begin{array}{c}0.420- \\
1.807\end{array}$ \\
\hline Diabetes Mellitus & 0.561 & 0.038 & $0.001-2319$ \\
\hline Hypertension & 0.323 & 0.329 & $\begin{array}{c}0.360- \\
2.987\end{array}$ \\
\hline Dyslipidaemia & 0.905 & 0.872 & $\begin{array}{c}0.092- \\
8.234\end{array}$ \\
\hline APLS & 0.508 & 0.036 & $\begin{array}{c}0.000- \\
672.6\end{array}$ \\
\hline $\begin{array}{l}\text { Cardiac disease (MI, stroke, } \\
\text { TIA) }\end{array}$ & 0.873 & 1.071 & $\begin{array}{c}0.463- \\
2.476\end{array}$ \\
\hline Donor source living & 0.353 & 0.459 & $\begin{array}{c}0.089- \\
2.372\end{array}$ \\
\hline Graft Failure post $r T p$ & 0.314 & 2.073 & $\begin{array}{c}0.501- \\
8.567\end{array}$ \\
\hline
\end{tabular}

exposed to glucocorticoids. $40 \%$ had active renal disease at least once during the study period, and active renal disease was observed in $22 \%$ of visits $(n=1238$ visits). $41 \%$ of patients had organ damage at baseline and $14 \%$ accrued organ damage (272 damage accrual episodes in 250 patients). Active renal disease was significantly associated with damage accrual; after adjusting for confounders, patients with active renal disease were $66 \%$ more likely to accrue organ damage compared to those without active renal disease (adjusted hazard ratio=1.66 (95\% Cl: $1.26,2.19$ ), p-value $<0.01$ (table 1). High cumulative GC and age were also significantly associated with damage accrual.

\begin{tabular}{|l|rll|rll|}
\hline & \multicolumn{3}{|c|}{$\begin{array}{c}\text { Univariable Cox } \\
\text { regression analysis }\end{array}$} & \multicolumn{4}{c|}{$\begin{array}{c}\text { Multivariable Cox } \\
\text { regression analysis }\end{array}$} \\
\hline & HR & $(95 \% \mathrm{Cl})$ & $\mathrm{p}$-value & HR & $(95 \% \mathrm{Cl})$ & $\mathrm{p}$-value \\
\hline Age at baseline (years) & 1.02 & $(1.01,1.03)$ & $<0.01$ & 1.02 & $(1.01,1.03)$ & $<0.01$ \\
Asian ethnicity & 0.74 & $(0.52,1.05)$ & 0.09 & 0.72 & $(0.50,1.04)$ & 0.08 \\
Cumulative glucocorticoid (GC) & & & & & & \\
categories & & & & & & \\
$\quad$ No GC & 1.00 & $(1.00,1.00)$ & & 1.00 & $(1.00,1.00)$ & \\
$\quad$ Low GC (Smedian PNL) & 1.42 & $(0.94,2.14)$ & 0.1 & 1.47 & $(0.97,2.23)$ & 0.07 \\
$\quad$ High GC (>median PNL) & 1.51 & $(1.04,2.18)$ & 0.03 & 1.46 & $(0.99,2.16)$ & 0.05 \\
Baseline organ damage present & 1.56 & $(1.22,2.00)$ & $<0.01$ & 1.27 & $(0.97,2.23)$ & 0.09 \\
Active lupus nephritis & 1.66 & $(1.29,2.14)$ & $<0.01$ & 1.66 & $(1.26,2.19)$ & $<0.01$ \\
\hline
\end{tabular}

Conclusions: Active LN is an independent risk factor for damage accrual in SLE. The concomitant independent association of GC exposure with damage accrual suggests non-GC treatments to reduce active $\mathrm{LN}$ are needed to reduce damage burden in SLE.

Disclosure of Interest: None declared

DOI: 10.1136/annrheumdis-2018-eular.4328

\section{THU0351 \\ SUSCEPTIBILITY TO CEREBRAL ISCHEMIA IN EARLY LUPUS PATIENTS: A PILOT STUDY OF CO- REGISTRATION WITH CONVENTIONAL BRAIN MRI, DIFFUSION- AND PERFUSION-WEIGHTED IMAGING}

${ }^{1}$ E. Silvagni, A. Revenaz ${ }^{2}$, A. Bortoluzzi ${ }^{1}$, E. Groppo ${ }^{3}$, M. Padovan ${ }^{1}$, M. Borrelli², S. Ceruti ${ }^{2}$, C.A. Scirè ${ }^{1}$, E. Fainardii ${ }^{4}$, M. Govoni ${ }^{1} .{ }^{1}$ Department of Medical Sciences, Rheumatology Unit, University of Ferrara; ${ }^{2}$ Neuroradiology Unit, Department of Neuroscience and Rehabilitation, Azienda Ospedaliero-Universitaria Sant'Anna, Cona; ${ }^{3}$ Neurorehabilitation Unit, MS Center, Foundation Don Gnocchi, Milan; ${ }^{4}$ Neuroradiology Unit, Department of Experimental and Clinical Biomedical Sciences, University of Florence, Florence, Italy

Background: Conventional brain Magnetic Resonance Imaging (cMRI) has a limited usefulness in patients with early diagnosis of Systemic Lupus Erythematosus (SLE), showing not specific abnormalities in up to half of the patients. No data are available about cMRI combined with advanced MRI techniques in early SLE patients.

Objectives: To evaluate differences between early SLE patients, even without overt neuropsychiatric (NP) manifestations, and healthy controls (HCs) in a mono centric cohort, using data derived from cMRI, diffusion-weighted imaging (DWI) and perfusion-imaging (PWI).

Methods: Patients referred to a single tertiary rheumatologic centre with early diagnosis of SLE (less than 24 months), aged less than 55, were consecutively enrolled (01/05/2013-31/12/2017) and imaged with CMRI, DWI and PWI (1.5 Tesla Philips "Signa Achieva" scanner). Data were analysed with a semiautomated measuring system (Diffusion/Perfusion Project Suite, developed in Multiple Sclerosis patients) to co-registrate apparent diffusion coefficient $(A D C)$, cerebral blood flow (CBF) and volume (CBV), mean transit time (MTT) in normal appearing grey (NAGM) and white matter (NAWM), deep GM (putamen, pallidus, caudate, thalamus) and lesions. Demographic, clinical, serological and treatment information were collected as well as NP events at baseline attributed to SLE according to a validated algorithm. Statistical analysis were performed by comparing median (interquartile range, IQR) values for skewed variables between SLE and HCs and with quantile regression adjusted for cardiovascular comorbidities (hypertension, diabetes, previous coronary heart disease, hyperlipidaemia, obesity)

Results: 30 patients with early SLE (mean age 37.0 years, standard deviation SD 10.7, 27 females) and 8 HCs (mean age 40.6, SD 11.2, 6 females) were enrolled. MRI was performed after a mean period of 259 days from diagnosis; mean (SD) Systemic Lupus Erythematosus Disease Activity Index 2000 (SLEDAI-2k) was 8.87 (3.85) while mean (SD) Systemic Lupus International Collaborating Clinics/ American College of Rheumatology Damage Index (SDI) was 0.40 (0.72); 3 patients were classified as NPSLE at diagnosis. Median (IQR) values of ADC in NAGM and NAWM were $1.15 \times 10-3 \mathrm{~mm} 2 / \mathrm{s}(1.12-1.16)$ and $0.86(0.85-0.88)$ in SLE, 1.28 (1.16-1.33) and $0.97(0.87-0.98)$ in HCs respectively (table 1). After adjusting for comorbidities, median differences between ADC values remained significant $(p<0.001)$. SLE patients had lower median ADC values at bilateral putamen and pallidus. No differences were found in perfusion parameters in all the regions of interest (ROI) and lesions. A trend towards lower CBV and CBF and higher MTT values for NAGM-NAWM in NPSLE compared to non-NPSLE was found.

Abstract THU0351 - Table 1. Differences in diffusion and perfusion parameters at norma appearing GM and WM level in SLE patients and HCs.

\begin{tabular}{|c|c|c|c|c|c|c|c|c|}
\hline ROI & $\begin{array}{l}\text { NAGM } \\
\text { ADC }\end{array}$ & $\begin{array}{l}\text { NAWM } \\
\text { ADC }\end{array}$ & $\begin{array}{l}\text { NAGM } \\
\text { CBFF }\end{array}$ & $\begin{array}{l}\text { NAWM } \\
\text { CBF }\end{array}$ & $\begin{array}{l}\text { NAGM } \\
\text { CBV }\end{array}$ & $\begin{array}{l}\text { NAWM } \\
\text { CBV }\end{array}$ & $\begin{array}{l}\text { NAGM } \\
\text { MII }\end{array}$ & $\begin{array}{l}\text { NAWM } \\
\text { MIII }\end{array}$ \\
\hline $\begin{array}{l}\text { SLE(30), } \\
\text { median } \\
\text { (IQR) }\end{array}$ & $\begin{array}{l}1.15 \\
(1.12- \\
1.16)\end{array}$ & $\begin{array}{l}0.86 \\
(0.85- \\
0.88)\end{array}$ & $\begin{array}{l}37.09 \\
(30.97- \\
47.21)\end{array}$ & $\begin{array}{l}29.42 \\
(26.00- \\
37.48)\end{array}$ & $\begin{array}{l}2.43 \\
(2.20- \\
2.58)\end{array}$ & $\begin{array}{l}1.95 \\
(1.80- \\
2.26)\end{array}$ & $\begin{array}{l}4.31 \\
(3.80- \\
5.23)\end{array}$ & $\begin{array}{l}4.87 \\
(4.12- \\
5.85)\end{array}$ \\
\hline $\begin{array}{l}\text { HCS (8), } \\
\text { median } \\
\text { (IQR) }\end{array}$ & $\begin{array}{l}1.28 \\
\text { (1.16- } \\
1.33)\end{array}$ & $\begin{array}{l}0.97 \\
(0.87- \\
0.98)\end{array}$ & $\begin{array}{l}33.89 \\
(25.38- \\
47.79)\end{array}$ & $\begin{array}{l}26.54 \\
\text { (20.16. } \\
39.79)\end{array}$ & $\begin{array}{l}2.57 \\
(2.19- \\
3.07)\end{array}$ & $\begin{array}{l}2.11 \\
(1.77- \\
2.54)\end{array}$ & $\begin{array}{l}5.11 \\
(4.11- \\
6.18)\end{array}$ & $\begin{array}{l}5.78 \\
(4.58- \\
6.72)\end{array}$ \\
\hline p & 0.004 & 0.009 & 0.591 & 0.519 & 0.283 & 0.452 & 0.123 & 0.124 \\
\hline
\end{tabular}

Conclusions: Lower ADC values in normal appearing GM and WM in early SLE patients could reflect susceptibility to cerebral ischemia, partially confirmed analysing perfusional data in NPSLE patients. Further prospective studies with higher sample size are necessary to confirm these findings.

\section{REFERENCES}

[1] Petri, et al. J Rheum 2008.

[2] Bortoluzzi, et al. Rheumatology (Oxford) 2015.

[3] Revenaz, et al. BMC Med Imaging 2016.

[4] Papadaki, et al. Ann Rheum Dis 2017.

Disclosure of Interest: None declared

DOI: 10.1136/annrheumdis-2018-eular.5702 
THU0352

ASSOCIATION BETWEEN MEMORY B-CELLS AND PHENOTYPIC FEATURES OF SJÖGREN'S SYNDROME

${ }^{1,2,3}{ }^{2}$. Barcelos, C. Martins ${ }^{1}$, A.L. Papoila ${ }^{4}$, C. Geraldes ${ }^{4}$, J. Cardigos $^{5}$, G. Nunes ${ }^{1}$, T. Lopes ${ }^{1}$, N. Alves ${ }^{5}$, J. Vaz-Patto ${ }^{2}$, J.C. Branco ${ }^{1,3}$, L.M. Borrego ${ }^{1} .{ }^{1}$ CEDOC, Nova Medical School; ${ }^{2}$ Rheumatology, Instituto Português de Reumatologia;

${ }^{3}$ Rheumatology, Hospital Cuf Descobertas; ${ }^{4}$ Nova Medical School; ${ }^{5}$ Ophthalmology, CHLC, Hospital de Santo António dos Capuchos, Lisbon, Portugal

Background: B-cell disturbances are a hallmark of pSS and play a pivotal role in the disease pathogenesis and clinical evolution, and may as well have a potential role in diagnosis. In pSS, an increase of the naïve subset and a decrease of memory B-cells have been reported. A decreased frequency of memory cells has also been identified in patients with Sicca syndrome without criteria for pSS

Objectives: Our study aims to evaluate the distribution of B-lymphocyte subpopulations in pSS and Sicca patients and to establish cut-off points for pSS classification in relation to healthy controls. Moreover, we aim to evaluate the relation between lymphocyte subpopulations and phenotypic features in pSS.

Methods: Fifty-seven pSS patients, 68 non-Sjögren Sicca patients and 24 healthy controls were included. Circulating B-cell frequencies were determined by flow cytometry, and the naïve and memory (switched and unswitched) subsets were characterised based on surface marker expression of the following monoclonal antibodies: CD19, CD24, CD27, Anti-IgD and Anti-IgM.

Kruskal-Wallis test was applied for groups' comparison. ROC curves were used to establish cut-off points in the B-cells subset levels and to estimate corresponding sensitivity and specificity. Data analysis was performed with $R$ software.

Results: Absolute numbers of lymphocytes in pSS were lower compared to controls, with Sicca presenting intermediate levels.

Significant differences were found between pSS and controls in absolute counts of all memory populations: total memory (TMem) $\left(\mathrm{CD} 19^{+} \mathrm{CD} 27^{+}\right)$, switched (SwM) $\left(\mathrm{CD} 19^{+} \operatorname{lgD}{ }^{-} \mathrm{CD} 27^{+}\right)$and unswitched memory (UnSwM) $(\mathrm{p}<0.001$ for all). Comparing pSS with controls, we found lower percentages of TMem in patients $(p=0.078$ and more significant differences in the UnSwM subset $(p=0.043)$. Percentages of memory B-cells in Sicca were not significantly different from pSS and controls. Absolute memory B-cells numbers in Sicca were intermediate between those of pSS and controls.

Through ROC curves, the B-cell subsets that better discriminate between pSS and controls were TMem and SwM. A cut-off of equal to $58 \mathrm{TMem}$ cells/ $\mathrm{\mu l}$ yelded a specificity of 0.88 and a sensitivity of 0.60 for pSS, and was met by $59.6 \%$ of pSS, $12.5 \%$ of controls and $38.8 \%$ of Sicca, and a cut-off of equal to 23.5 SwM cells/ $\mu$ lyelded a specificity of 0.88 and a sensitivity of 0.54 and was met by $54.4 \%$ of pSS, $12.5 \%$ of controls and $37.3 \%$ of Sicca.

pSS patients with lower values than the established cut-off points had longer disease duration, higher disease activity (ESSDAI), and were more likely to present auto-antibodies and positive biopsy. Several Sicca patients also presented memory B-cell subsets counts lower than the pSS cut-off, but no consistent differences in clinical profile were identified.

Conclusions: Decreased numbers of memory B-cell subsets clearly discriminate pSS from healthy controls. Lower memory B-cells counts are associated with more active pSS disease profile. It remains to be clarified whether Sicca patients with decreased memory B-cells represent pSS and if B-cell profiling could help in the diagnosis of pSS.

Disclosure of Interest: None declared

DOI: 10.1136/annrheumdis-2018-eular.5717

\section{THU0353 LUNG ULTRASOUND OF PLEURAL IRREGULARITIES (PI-US) IN PRIMARY SJÖGREN'S SYNDROME (PSS)- ASSOCIATED INTERSTITIAL LUNG DISEASE(ILD): CLINICAL, FUNCTIONAL, RADIOGRAPHIC AND ULTRASONOGRAPHIC SHORT-TERM FOLLOW-UP}

${ }^{1}$ F. Ferro, A. Bulleri ${ }^{2}$, A. Delle Sedie ${ }^{1}$, S. Barsotti ${ }^{1}$, N. Luciano ${ }^{1}$, E. Elefante ${ }^{1}$, M. Mosca ${ }^{1}$, C. Baldini ${ }^{1} .{ }^{1}$ Rheumatology Unit, University of Pisa; ${ }^{2}$ Radiology Unit, University of Pisa, Pisa, Italy

Background: Ultrasound of Pleural Irregularities (PI-US) has recently been suggested as a useful tool for the diagnosis and the assessment of interstitial lung disease (ILD) in primary Sjögren's Syndrome (pSS). However, no data are available regarding its role in the post-therapy evaluation of pSS-ILD.

Objectives: Aim of this study was to describe the post-therapeutic changes of the pleural profile in a monocentric cohort of pSS-ILD patients analysing clinical, functional, US and radiographic features.

Methods: Eighteen patients with pSS-ILD were included in the study. PI-US, HRCT and pulmonary function test (PFT) were performed in each patient at baseline. In 15/18 patients who had been treated according to international guidelines for ILD, clinical assessment, PFT and PI-US were repeated after 6 months. PI-US was performed by a single operator using a MyLab-25 (Esaote), $10 \mathrm{MHz}, 5 \mathrm{~cm}$ linear probe. PI was defined as the loss of normal hyperechoic linear pleural contour (score 0-2: normal, minimal and major changes at each intercostal space). PI-US total score represented the sum of partial scores assigned to 6 lung fields ( $2 \mathrm{for}$ the anterior, 2 for postero-superior and 2 for postero-inferior chest surface). HRCT- abnormal findings, distinguishing C-NSIP, F-NSIP and UIP pattern, were quantified using the Warrick score system

Results: Eighteen pSS-ILD patients ( $14 \mathrm{~F}: 4 \mathrm{M}$, mean age $=68.8 \pm 9.9$ years) were included in the study. The median PI-US score was 45 (range 25.5-73.5). Both $\mathrm{PI}$-US total score and partial postero-inferior PI-US score strongly correlated with the Warrick HRCT score $(r=0.813, p=0.000$ and $r=0.914, p=0.000)$ and inversely correlated with FVC $(r=-0.849, p=0.000$ and $r=-0.836, p=0.000)$, TLC $(r=-0.895$ $\mathrm{p}=0.000$ and $\mathrm{r}=-0.829, \mathrm{p}=0.000)$, and DLCO $(\mathrm{r}=-0.953, \mathrm{p}=0.000$ and $\mathrm{r}=-0.883$, $\mathrm{p}=0.001)$. Both PI-US score and PI-US of the poster-inferior field directly corre lated with FEV1/SVC $(r=0.701, p=0.004$ and $r=0.619, p=0.01)$ and with FEV1/ FVC $(r=0.600, p=0.02$ and $r=0.501, p=0.05)$. After 6 months of therapy, 15 patients (12F:3M, mean age 65.3 years) presenting at HRCT different ILD pattern distributions (4 C-NSIP, 7 F-NSIP, 4 UIP), were re-evaluated after appropriate medical treatment. Out of these 15 patients, 5 had been treated with glucocorticoids (GC) alone, 2 with azathioprine, 4 with hydroxychlorochine, 2 with Mycophenolate Mofetil, 1 with Rituximab and 1 with abatacept. Clinical, radiographic and functional evaluation showed stability of all parameters in the majority of the patients (13/15), maintaining unchanged the correlations with PI-US scores Moreover, 2/15 patients with active C-NSIP pattern, showed a significant improvement in clinical, radiographic and functional parameters. In these patients a significant reduction of the PI-US scores was also observed (PI-US score from 22 to 10 and from 57 to 30 ).

Conclusions: This study confirms the usefulness of PI-US evaluation for the diagnosis and assessment of pSS-ILD, demonstrating a strong correlation between PI-US and both HRCT findings and PFT. Furthermore, the significant reduction of $\mathrm{PI}$-US score in patients with clinical, radiographic and functiona improvement suggests that this tool may play a role in the follow-up of treated patients with active pSS-ILD.

Disclosure of Interest: None declared

DOI: 10.1136/annrheumdis-2018-eular.5955

\section{THU0354 IMPACT OF BIOLOGIC THERAPY IN SJOGREN'S SYNDROMEPATIENTS WITH OVERLAPPING AUTOIMMUNE DISEASES OR EXTRAGLANDULAR MANIFESTATIONS. A SYSTEMATIC REVIEW OF LITERATURE}

${ }^{1}$ G.E. Fragoulis, E. Nikiphorou ${ }^{2}$, A. Alunno ${ }^{3}, \mathrm{~F} . \mathrm{Ng}^{4}$, A.G. Tzioufas ${ }^{5} .{ }^{1}$ Institute of Infection, Immunity and Inflammation, University of Glasgow, Glasgow; ${ }^{2}$ Academic Rheumatology Department, King's College London, London, UK; ${ }^{3}$ Rheumatology Unit, University of Perugia, Perugia, Italy, ${ }^{4}$ Institute of Cellular Medicine, University of Newcastle, Newcastle, UK; ${ }^{5}$ Pathophysiology Department, University of Athens, Athens, Greece

Background: Treatment of Sjogren's syndrome (SS) has traditionally focused on conventional synthetic DMARDs (csDMARDs), with encouraging evidence on the benefit of biologic therapies emerging, mainly for treatment of SS extraglandular manifestations. Overlapping autoimmune diseases in SS are poorly studied; yet evidence primarily from case reports suggest a beneficial effect with biologics. Objectives: To systematically review the literature on the treatment of SS with biologics, taking a focus on case reports and overlapping autoimmune conditions or extraglandular manifestations (defined here as those described in the EULAR SS disease activity index - ESSDAI)

Methods: A literature review was performed independently by two reviewers, using Pubmed and the following search terms: "Sjogren" or "Sjogren's" AND any of the following: "biologics", "Etanercept", "Adalimumab", "Infliximab", "Golimumab", "Certolizumab", "Tocilizumab", "Abatacept", "Rituximab", "Belimumab", "Secukinumab", "Ustekinumab" and "Anakinra". Inclusion criteria were: articles in English; published until January 2018; case reports of patients with primary or secondary SS. Initial screening was based on title/abstract, followed by full-text review for articles fulfilling inclusion criteria. For articles written in a different language, information was obtained from abstract if available, otherwise excluded Concordance in article screening was $95 \%$ across the two reviewers. Data extraction focused on reporting overlapping autoimmune diseases and extraglandular manifestations, treatment and response data.

Results: Out of 679 papers screened, 39 articles were included. 22 overlapping autoimmune conditions were reported in 22 SS patients (table 1). Most of the patients were treated with Rituximab $(63.6 \%)$, while TNF-inhibitors $(22.7 \%)$, Tocilizumab (9.1\%) and Ustekinumab (4.5\%) were also used. Concurrent treatment with csDMARDs and steroids was used in $28.6 \%$ and $42.9 \%$ of the cases, respectively. $61.9 \%$ and $13.6 \%$ of the patients were csDMARDs- and biologic- experienced, respectively. Good response of overlapping condition was seen in $86.4 \%$ of them, while in $13.6 \%$, control or partial response was reported. Although, most of the studies do not mention the effect of biologic treatment on SS, genera 